\title{
Brain IL-1-Induced Immunosuppression Occurs Through Activation of Both Pituitary-Adrenal Axis and Sympathetic Nervous System by Corticotropin-Releasing Factor
}

\author{
Syam K. Sundar, ${ }^{1}$ Mark A. Cierpial, ' Clinton Kilts, ${ }^{1,2}$ James C. Ritchie,' and Jay M. Weiss' \\ Departments of ${ }^{1}$ Psychiatry and ${ }^{2}$ Pharmacology, Duke University Medical Center, Durham, North Carolina 27710.
}

\begin{abstract}
Intracerebroventricular infusion of femtomolar quantities of interleukin-1 (IL-1) or stimulated release of endogenous IL-1 in the brain suppresses various cellular immune responses, decreasing natural killer cell (NK) activity, response to mitogen, and interleukin-2 production of splenic and blood lymphocytes (an effect hereafter called "brain IL-1-induced immunosuppression"). The present study examines mechanisms by which IL-1 produces this effect. First, because IL-1 in the brain activates the pituitary-adrenal axis by stimulating release of corticotropin-releasing factor (CRF), the role of CRF was investigated. To block CRF, affinity-purified antibody to CRF was infused into the lateral ventricle $30 \mathrm{~min}$ before introduction of IL-1. When this was done, suppression of cellular immune responses that normally follow IL-1 infusion was completely prevented. Infusion with an equal quantity of non-CRF IgG prior to IL-1 was without effect. Second, the role of sympathetic nervous activity was examined. To block neural transmission at sympathetic ganglia, chlorisondamine $(3.0 \mathrm{mg} / \mathbf{k g})$ was injected intraperitoneally $60 \mathrm{~min}$ before IL-1 infusion. When this was done, suppression of immune responses by IL-1 was partially blocked. These results indicate that IL-1 in the brain suppresses various cellular immune responses by activating both the pituitary-adrenal axis and the sympathetic nervous system, and that these systems are both activated through the influence of IL-1 on CRF.
\end{abstract}

Elevation of interleukin-1 (IL-1) in the brain, either by infusion of IL-1 into the lateral ventricle or by stimulation of release of endogenous IL-1, produces dramatic, rapid, and long-lasting immunosuppression as measured by various indices of cellmediated immune function (Sundar et al., 1989). That IL-1 can affect immune responses by acting in the brain is consistent with reports that IL-1 affects the CNS (Dinarello, 1984; Krueger et al., 1984; Tobler et al., 1984; Besedovsky et al., 1986; Berkenbosch et al., 1987; Bernton et al., 1987; Sapolsky et al., 1987) and may well act as a neurotransmitter and neuromodulator (Breder et al., 1988). The present study investigates the pathways activated by IL-1 in the brain to affect immune responses of peripheral lymphocytes.

\footnotetext{
Received Feb. 8, 1990; revised June 14, 1990; accepted July 23, 1990.

This work was supported by U.S. Public Health Service Grant MH45675 and funds from the Behavioral Medicine Research Center (BMRC) of Duke University. We gratefully acknowledge the gift of Ecolid (chlorisondamine) from Ciba Geigy Corporation.

Correspondence should be addressed to Dr. Jay M. Weiss, Department of Psychiatry, Box 3829 Duke University Medical Center, Durham, NC 27710.

Copyright (C) 1990 Society for Neuroscience $0270-6474 / 90 / 113701-06 \$ 03.00 / 0$
}

Reduction in immune functions of peripheral lymphocytes following elevation of IL-1 in the brain (i.e., "brain IL-1-induced immunosuppression") appears to occur through action of multiple physiological pathways. IL-1 in the brain stimulates release of ACTH and thereby elevates plasma corticosterone (Besedovsky et al., 1986; Berkenbosch et al., 1987; Bernton et al., 1987; Sapolsky et al., 1987; Sundar et al., 1989), which is well known to be immunosuppressive (Gillis et al., 1979; Cohen and Crnic, 1982). IL-1 in the brain also appears to inhibit peripheral immune responses by activating neural pathways. Evidence for this is as follows: (1) brain IL-1-induced immunosuppression is observed in adrenalectomized animals, indicating that the decreased immunological responses are, at least in part, independent of elevations in plasma corticosterone; and (2) immune responses of splenic lymphocytes are reduced by a lower amount of IL-1 in the brain than is needed to reduce responses of blood lymphocytes, suggesting that splenic lymphocytes are affected by an influence not present in blood, that is, a neural, possibly autonomic, pathway to the spleen activated by IL-1. That autonomic activation can inhibit cellular immune responses is also well known (reviewed by Felten et al., 1987).

In these experiments, we examined the possibility that brain IL-1-induced immunosuppression is mediated through the action of corticotropin-releasing factor (CRF) in the brain and the sympathetic nervous system in the periphery. IL-1 in the brain stimulates release of CRF (Sapolsky et al., 1987; Katsuura et al., 1988a), which not only activates the hypothalamic-pituitary adrenal (HPA) axis, but also stimulates the sympathetic nervous system (Brown et al., 1982; Brown and Fisher, 1985). To investigate the role CRF might play in immunosuppression caused by brain IL-1, we determined whether neutralization of CRF in the brain by ventricular infusion of a purified antibody to CRF would prevent subsequent infusion of IL-1 from suppressing immune responses. To investigate the role of the sympathetic nervous system in brain IL-1-induced immunosuppression, we determined whether pharmacological blockade of sympathetic neural transmission also would prevent infusion of IL-1 from suppressing immune responses.

\section{Materials and Methods}

Subjects. Subjects were male Sprague-Dawley rats, weighing 200-300 $\mathrm{gm}$, obtained from Charles River Breeding Laboratories. Following receipt from the shipper, animals were housed 2 per cage directly on bedding for at least 2 weeks in the colony. Animals in the colony are kept in enclosed, laminar-flow racks of a design developed by Riley et al. (1981). In these racks, animals on any given shelf do not come in contact with the odors or noises of other animals in the colony; noise and disturbance in the colony was also kept to a minimum. 
Cannula implantation. For surgery, animals were removed from their cages and anesthetized with pentobarbital $(50 \mathrm{mg} / \mathrm{kg})$, and a permanent indwelling cannula was stereotaxically implanted into the lateral ventricle of each animal. Details of cannula design and surgical procedures are found in Weiss et al. (1986). Briefly, a cannula consisting of a 26gauge needle with Silastic tubing attached was lowered into the lateral ventricle. Placement of the cannula in the ventricle was confirmed by the rising of cerebrospinal fluid in the cannula, after which the cannula was fixed in place by dental cement applied to the skull. Following surgery, animals were returned to the colony and housed individually.

Infusion. Four to $6 \mathrm{~d}$ after surgery, each animal in the study was removed from the colony and transported in its home cage to an adjoining room where infusion was carried out. Details of the infusion procedure also can be found in Weiss et al. (1986). Briefly, the cannula was opened, infusion tubing inserted into the cannula, and solution advanced to the tip of the cannula in the ventricle. The animal was then placed back into its home cage, and the infusion was begun. Infusion time and volume varied slightly depending on the substance infused (see Details of Specific Experiments, below). At the end of the infusion, the cannula was closed with a clip that restrained flow, and the animal was returned to the colony in its individual cage, placed into the same position in the animal rack it had occupied prior to removal.

$C R F$ antibody purification. In Experiment 1, animals were infused with either rabbit IgG immunoreactive for CRF (anti-CRF IgG) or rabbit IgG nonimmunoreactive for CRF (non-CRF IgG). For these infusions, a polyclonal antibody against rat/human CRF was prepared and purified. The antibody was prepared by immunizing rabbits with rat/human CRF conjugated to keyhole limpet hemocyanin via glutaraldehyde, and the antiserum (a gift from Dr. Lothar Jennes, University of Dayton) was then purified by high-performance liquid chromatography (HPLC) using Protein A immobilized resin (50 × $4.6 \mathrm{~mm}$; Durasphere Protein A, 500A silica, Alltech, Deerfield, IL). An IgG fraction from $50 \mu$ of the antiserum was isolated and purified by discontinuous (step) gradient HPLC using an initial mobile phase (A) containing 10 mM $\mathrm{NaH}_{2} \mathrm{PO}_{4}$ and $100 \mathrm{mM} \mathrm{Na}_{2} \mathrm{SO}_{4}(\mathrm{pH}, 7.0)$ and a subsequent mobile phase (B) containing $10 \mathrm{~mm} \mathrm{NaH} \mathrm{PO}_{4}$ and $100 \mathrm{~mm} \mathrm{Na} \mathrm{SO}_{4}(\mathrm{pH}, 3.0)$. Mobile phase flow rates were $1.0 \mathrm{ml} / \mathrm{min}$. Following sample injection, the analyte was chromatographed using $100 \%$ mobile phase $\mathrm{A}$ for 5 min, followed by $100 \% \mathrm{~B}$. Peak identity and IgG concentration were determined by chromatographing varying amounts (25-500 $\mu \mathrm{g})$ of authentic rabbit IgG (Jackson Laboratories). Column eluate was monitored by a variable wavelength UV absorbance detector $(280 \mathrm{~nm})$, and the eluate fraction corresponding to the $\operatorname{IgG}$ peak was manually collected. Non-CRF IgG was obtained by collecting IgG similarly isolated and purified from normal rabbit serum.

Antigen binding capacity was determined by double-antibody equilibrium radioimmunoassay of serial dilutions of $\mathrm{IgG}$ solutions, using varying concentrations of rat/human CRF $(0.5-5000 \mathrm{pg})$ and a constant amount of ${ }^{125}$ I-CRF. Prior to ventricular infusion, the anti-CRF IgG solution and non-CRF IgG solution were dialyzed against $0.9 \% \mathrm{NaCl}$ for $12-14 \mathrm{hr}$ at $4^{\circ} \mathrm{C}$, then sterilized by filtration.

Details of specific experiments. In Experiment 1, animals were first infused with anti-CRF $\operatorname{lgG}$ or non-CRF IgG and subsequently infused with IL-1 or its vehicle. Infusion of $\mathrm{IgG}$ was carried out by slowly introducing the solution over a 5 -min period. Thirty minutes after conclusion of the IgG infusion, each animal's cannula was reopened, and the animal was then infused with either $100 \mathrm{pg}(10 \mu \mathrm{l})$ IL-1 (purified human recombinant IL-1 $\beta$, Genzyme, Boston, MA) or $10 \mu$ l vehicle, this infusion being carried out over an 8 -min period. Thus, this experiment utilized a $2 \times 2$ design, the 4 groups given infusions of (1) antiCRF IgG followed by IL-1, (2) non-CRF IgG followed by IL-1, (3) antiCRF IgG followed by vehicle, and (4) non-CRF IgG followed by vehicle. Fifteen minutes after completion of the IL-1 or vehicle infusion, animals were anesthetized with pentobarbital for immunological measurements. Three replications of this experiment were conducted $(A, B$, and $C)$. In the first replication (A), $5 \mu \mathrm{lgG}$ solution was infused (for details of immunological activity, see Results), while in the last 2 replications (B and $\mathrm{C}$ ), $15 \mu \mathrm{lgG}$ was infused. In each replication, $N=3$ per group.

In Experiment 2, animals were first injected with chlorisondamine or vehicle and subsequently infused with IL-1 or vehicle. Chlorisondamine (Ecolid, $3.0 \mathrm{mg} / \mathrm{kg})$ or vehicle $(0.9 \%$ saline) was injected intraperitoneally, and 60 min later, animals were infused intracerebroventricularly with $100 \mathrm{pg}$ IL-1 or vehicle as in Experiment 1. Thus, this experiment also utilized a $2 \times 2$ design, the 4 groups being (1) chlorisondamine followed by IL-1, (2) $0.9 \%$ saline followed by IL-1, (3) chlorisondamine followed by vehicle, and (4) $0.9 \%$ saline followed by vehicle. Two replications of this experiment were conducted; in each replication, $N=3$ per group. As in Experiment 1, animals were anesthetized for immunological measures 15 min after completion of IL-1 or vehicle infusion. It is important to point out that the dose of chlorisondamine given in this study is sufficient to completely block neural transmission through sympathetic ganglia (Seidler and Slotkin, 1979; Bartolome et al., 1980; Smith et al., 1984; Mills and Smith, 1986).

Immunological measures: collection of lymphocytes. Peripheral blood was collected by cardiac puncture within $5 \mathrm{~min}$ after the injection of anesthetic. Spleens were removed under sterile conditions. Splenic lymphocytes were extracted by gentle crushing of the spleens between sterile glass slides. Mononuclear cells then were separated on Ficoll-Hypaque density gradients. The number of viable lymphocytes in these preparations was counted by trypan blue dye exclusion.

Lymphocyte proliferation to phytohemagglutinin (PHA). To determine the lymphocyte response to stimulation by a mitogen, $0.1 \mathrm{ml}$ aliquots of lymphocyte suspension $\left(2 \times 10^{6}\right.$ cells $/ \mathrm{ml}$ in RPMI-1640 medium containing $10 \%$ heat-inactivated fetal calf serum, henceforth referred to as RPMI) were mixed with $10 \mu \mathrm{g} / \mathrm{ml}$ PHA. (All measures were carried out on triplicate samples.) After $3 \mathrm{~d}$ of incubation, the cultures were pulsed for $4 \mathrm{hr}$ with $1.0 \mu \mathrm{Ci}$ tritiated thymidine. Cells were then harvested onto glass-fiber filters using a semiautomatic Skatron cell harvester, and incorporated radioactive thymidine was determined in a liquid scintillation counter.

Interleukin-2 (IL-2) production by stimulated lymphocytes. Splenic lymphocytes were stimulated with $10 \mu \mathrm{g} / \mathrm{ml}$ PHA for $48 \mathrm{hr}$, after which culture supernatant was collected and the presence of IL-2 in the supernatant determined. To measure IL-2, IL-2-dependent CTLL cells were grown in RPMI 1640 medium to which culture supernatant was added as the sole source of IL-2. The ability of culture supernatant to support the growth of CTLL cells was determined by the incorporation of radioactive thymidine (method of Gillis et al., 1978).

Determination of natural killer (NK) cell activity. NK cell activity was determined by the lysis of ${ }^{51} \mathrm{Cr}$-labeled Yac-1 cells (method of Reynolds et al., 1981). Blood and splenic lymphocytes were used as effector cells, and an effector : target ratio of 50:1 was used in all experiments except one where effector: target ratios of 50:1, 25:1, and 10:1 were used.

Steroid assay. Plasma corticosterone was measured by a modification of the microscale competitive protein binding (CPB) technique originally described by Murphy (1967). The assay used is described in Naylor et al. (1988).

Statistical analysis. Statistical analysis of results for each measure was done by analysis of variance. One-way analyses were used except when more than 1 replication was carried out employing the same conditions, in which case, a 2-way analysis blocking for replication was used. Where a significant overall $F$ score was obtained, comparisons of individual groups were carried out by protected $t$ tests (Kirk, 1969).

\section{Results}

\section{Characterization of the CRF antibody (Experiment 1)}

Purification of the rabbit CRF antiserum yielded a relatively concentrated solution of IgG that possessed high biological activity for binding of CRF. Precipitation and quantification of serum proteins and measurement of binding activity indicated that approximately $4 \%$ of the serum proteins in the rabbit antiserum was $\mathrm{IgG}$, and approximately $1 \%$ of the $\mathrm{IgG}$ fraction was anti-CRF IgG. Chromatography of the Protein A-purified antiserum is shown in Figure 1. Chromatographic comparison of the purified column eluate used for infusion with a quantitative calibration curve revealed that the concentration of protein (i.e., IgG) in the purified eluate was $10 \mu \mathrm{g} / \mu \mathrm{l}$. For infusion, IgG was diluted to $150 \mathrm{ng} / \mu \mathrm{l}$; therefore, $0.75 \mu \mathrm{g} \mathrm{IgG}$ was infused in the first replication $(5 \times 150 \mathrm{ng})$, and $2.25 \mu \mathrm{g}$ in each of the 2 subsequent replications $(15 \times 150 \mathrm{ng})$. For infusion, non-CRF $\mathrm{IgG}$ was also adjusted to a concentration of $150 \mathrm{ng} / \mu \mathrm{l}$. Based on Scatchard analysis of the results from radioimmunoassay performed on serial dilutions of the column eluate, CRF binding capacity was calculated to be $2.3 \mathrm{ng} \mathrm{CRF} / \mu \mathrm{g}$ IgG. Non-CRF IgG purified similarly had no apparent CRF binding capacity. 


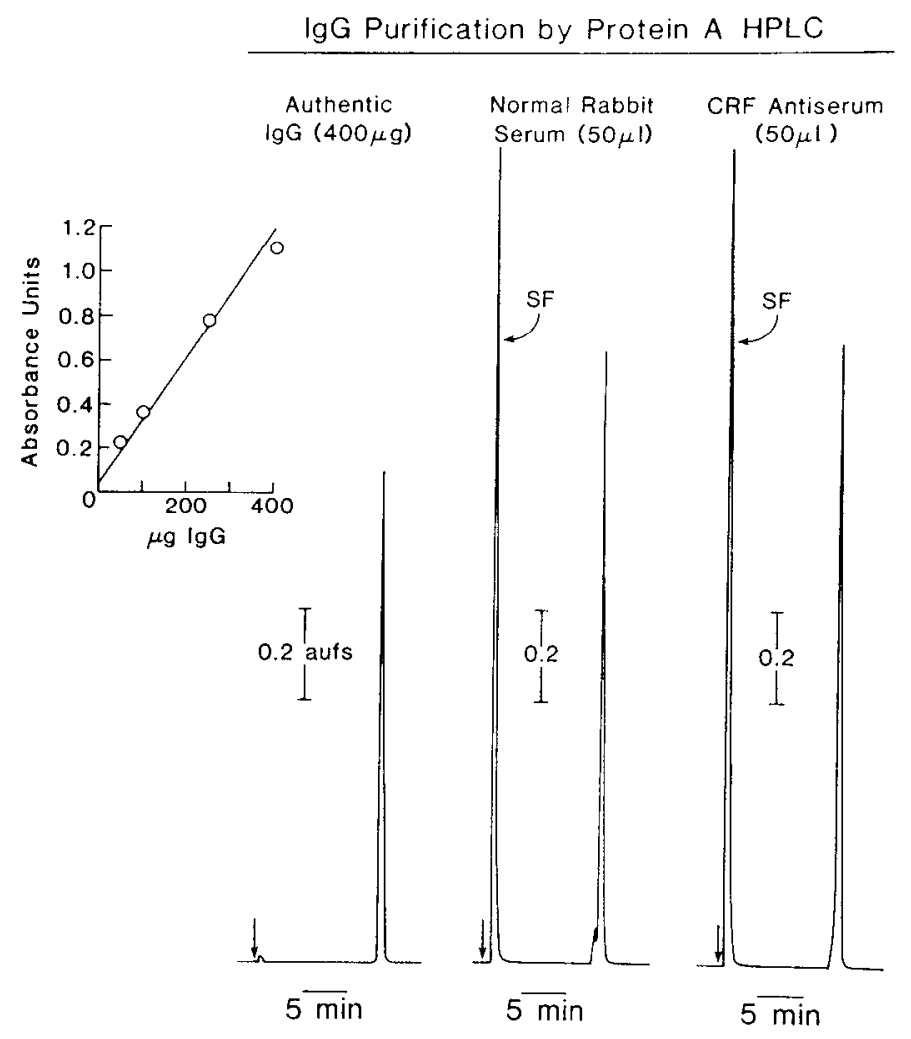

Figure 1. HPLC purification of IgG on Protein A-bonded silica. Chromatographic analysis is shown for IgG standard (authentic IgG), IgG from normal (preimmunized) rabbit serum (non-CRF IgG), and IgG from serum of animals immunized with CRF. SF, solvent front. Inset, Calibration curve relating detector response (absorbance units full scale) and amount of authentic IgG assayed.

Effects of CRF antibody infusion (Experiment 1). Infusion of anti-CRF IgG into the lateral ventricle completely blocked the ability of intracerebroventricular IL-1 to suppress various cellular immune responses. Effects measured in blood and splenic lymphocytes are shown in Figures 2 and 3 . As can be seen on the left side of Figures 2 and 3, the lower dose of antibody $(0.75$ $\mu \mathrm{g}$ ) infused in the first replication (A) only partially antagonized the ability of IL- 1 to suppress NK cell activity and T-cell mitogenesis (response to PHA). However, as can be seen in Table 1 , infusion of this quantity of anti-CRF IgG did not totally block the ability of intraventricular IL-1 to increase serum corticosterone, thereby indicating that the amount of anti-CRF IgG infused in the first replication was not sufficient to block entirely

\section{Blood Lymphocytes}

Low Dose (0.75 ug $\lg G$ ) High Dose (2.25 ug $\lg G)$
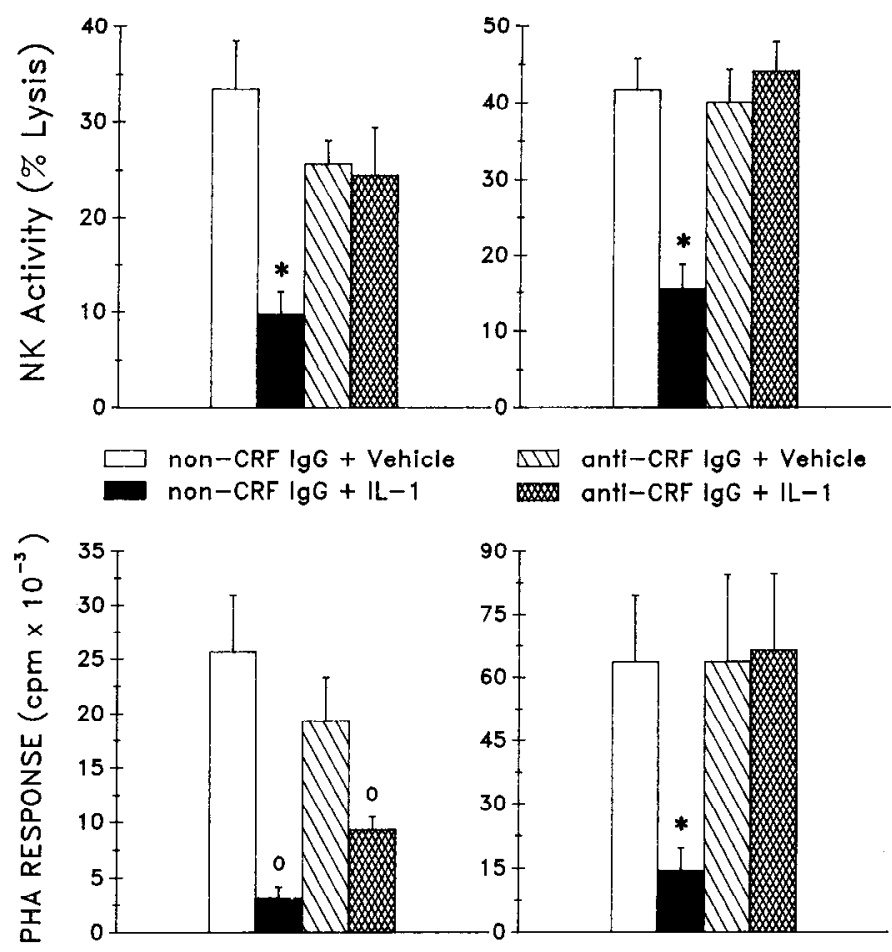

Figure 2. Cellular immune responses of blood lymphocytes following infusion of IL-1 or vehicle. Animals were infused with either non-CRF IgG or anti-CRF IgG in low dose $(0.75 \mu \mathrm{g})$ or high dose $(2.25 \mu \mathrm{g})$. Effects are shown on NK cell activity and response to PHA. Mean and SE for each group are shown. Asterisk, differs significantly (at least $p<$ $0.05)$ from each of the other 3 groups; open circle, differs significantly from each vehicle-infused group.

the activity of CRF that was induced by IL-1. However, as is evident in the right side of Figures 2 and 3, infusion of 3 times the dose of anti-CRF IgG used in the first replication (that is, $2.25 \mu \mathrm{g}$ ) totally blocked the ability of IL-1 to suppress NK cell activity, T-cell mitogenesis, and IL-2 production. As can be seen in Table 1, the higher dose of anti-CRF IgG completely blocked the ability of IL-1 in brain to increase serum corticosterone.

When a large number of effector cells is used in the NK assay, differences in NK activity might not be detected readily because the lysing of target cells may have reached a maximum. Thus, if intraventricular IL-1 partially diminished NK cell activity

Table 1. Plasma corticosterone concentration $(\mu \mathrm{g} / \mathrm{dl})$ in various groups

\begin{tabular}{|c|c|c|c|c|}
\hline \multirow[b]{2}{*}{ Experiment 1} & \multicolumn{2}{|c|}{ Non-CRF IgG } & \multicolumn{2}{|c|}{ Anti-CRF IgG } \\
\hline & IL-1 & Veh & IL-1 & Veh \\
\hline Replication A (0.75 $\mu \mathrm{g}$ lgG infused) & $53.4 \pm 1.7^{*}$ & $11.0 \pm 1.0$ & $32.8 \pm 5.9^{*}$ & $8.1 \pm 1.6$ \\
\hline \multirow[t]{2}{*}{ Replications B and C (2.25 $\mu \mathrm{g} \mathrm{IgG} \mathrm{infused})$} & $43.5 \pm 7.5^{*}$ & $14.5 \pm 2.1$ & $13.1 \pm 2.9$ & $12.6 \pm 2.6$ \\
\hline & \multicolumn{2}{|l|}{ Saline $(0.9 \%)$} & \multicolumn{2}{|c|}{ Chlorisondamine } \\
\hline \multirow[t]{2}{*}{ Experiment 2} & IL-1 & Veh & IL-1 & Veh \\
\hline & $48.6 \pm 4.6^{*}$ & $17.4 \pm 2.9$ & $50.9 \pm 6.2^{*}$ & $15.4 \pm 1.9$ \\
\hline
\end{tabular}

*, Differs significantly (at least $p<0.05$ ) from animals infused with non-CRF IgG and vehicle (experiment 1 ) or saline and vehicle (experiment 2 ). 


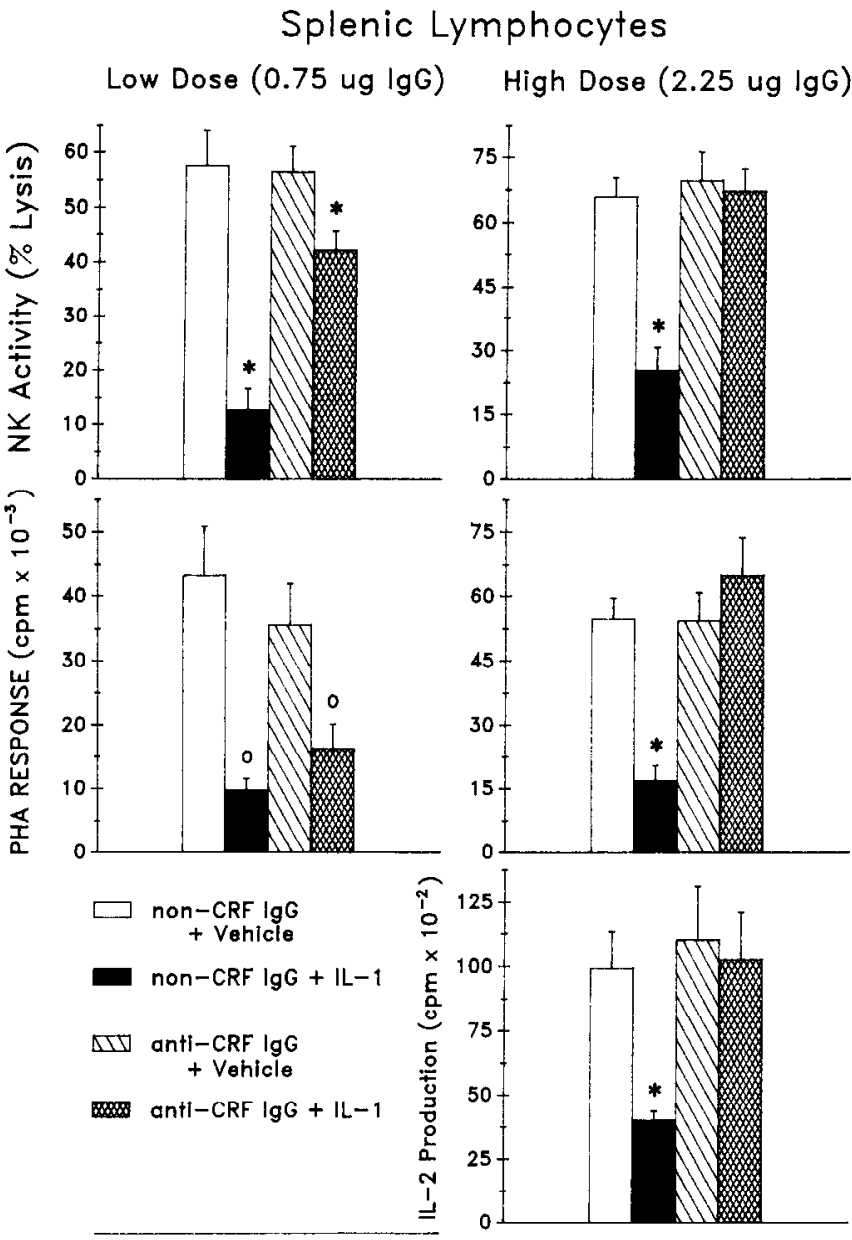

Figure 3. Cellular immune responses of splenic lymphocytes following infusion of IL-1 or vehicle. Animals were infused with either control $\operatorname{IgG}$ (non-CRF IgG) or anti-CRF IgG in low dose $(0.75 \mu \mathrm{g})$ or high dose $(2.25 \mu \mathrm{g})$. Effects are shown on NK cell activity, response to PHA, and IL-2 production. Mean and SE for each group are shown. Asterisk, differs significantly (at least $p<0.05$ ) from each of the other 3 groups; open circle, differs significantly from each vehicle-infused group.

despite the prior infusion of anti-CRF IgG, this might not be seen when the effector: target cell ratio was 50:1. However, diminished activity of NK cells should become apparent if a smaller number of effector cells were used so as not to reach a possible "ceiling" in the sensitivity of the assay. Therefore, the NK cell assay was carried out using reduced effector : target cell ratios as well as the 50:1 ratio. Figure 4 shows NK cell activity tested at 3 effector : target cell ratios when the higher dose $(2.25$ $\mu \mathrm{g}$ ) of anti-CRF IgG was infused (these data were generatcd in replication $\mathrm{C}$ ). Decreasing the number of effector cells relative to target cells did not reveal any impairment in NK function following IL-1 when anti-CRF IgG had been first infused.

\section{Effects of chlorisondamine injection (Experiment 2)}

Peripheral injection of chlorisondamine in a dose that is known to block completely sympathetic nervous transmission diminished the ability of intraventricular IL-1 to suppress various cellular immune responses of peripheral lymphocytes. As can be seen in Figure 5, chlorisondamine injection $60 \mathrm{~min}$ before infusion with IL-1 partially blocked, in both blood and splenic lymphocytes, the suppression of NK cell activity, response to

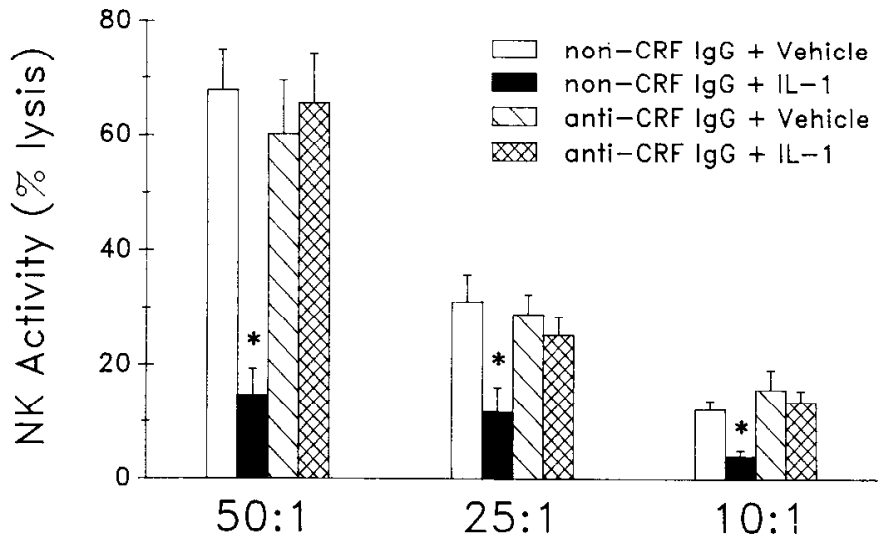

Figure 4. NK cell activity of animals infused with IL-1 or vehicle following infusion of either non-CRF IgG or anti-CRF IgG. Effects measured at 3 different ratios of effector : target cells are shown $(50: 1$, 25:1, and 10:1). Mean and SE for each group are shown. Asterisk, differs significantly (at least $p<0.05$ ) from each of the other 3 groups.

PHA, and IL-2 production produced by IL-1. However, it is equally clear that blockade of peripheral sympathetic transmission did not totally eliminate the ability of IL- 1 in the brain to suppress cellular immune responses; animals infused with IL-1 following the injection of chlorisondamine showed significant reduction of all immune parameters measured relative to animals not infused with IL-1 (i.e., relative to animals injected with $0.9 \%$ saline followed by vehicle infusion and animals injected with chlorisondamine followed by vehicle infusion). Regarding the influence of chlorisondamine injection on the elevation of plasma steroids normally observed after infusion of IL-1, Table 1 shows that, unlike infusion of anti-CRF IgG, which completely blocked the ability of IL-1 infusion to clevatc scrum corticosterone, injection of chlorisondamine prior to IL-1 infusion did not diminish the elevation of serum corticosterone produced by IL-1.

\section{Discussion}

The present results demonstrate that immunoneutralization of CRF by infusion of an antibody to CRF into the lateral ventricle was able to completely prevent suppression of a variety of cellular immune responses normally produced by infusion of IL-1 into the lateral ventricle. Experiment 1 showed that, when a sufficient quantity of anti-CRF IgG was infused to prevent activation of the pituitary-adrenal axis by ventricular infusion of IL-1, suppression by IL-1 of mitogenic response to PHA, NK cell activity, and IL-2 production in both blood and splenic lymphocytes by IL-1 was no longer seen. Therefore, suppression of cellular immunc responses occurring in response to IL-1 in the brain is mediated by the ability of IL-1 to stimulate activity of CRF in the brain.

In an earlier experiment, Sundar et al. (1989) showed that infusion of IL-1 into animals with their adrenals removed still resulted in partial suppression of cellular immune responses, thereby indicating that brain IL-1-induced immunosuppression was only partially mediated by elevation of serum corticosteroids. This finding added to a growing number showing that manipulations that suppress cellular immune responses while also increasing circulating corticosteroids do not necessarily produce the immunosuppression solely, or even largely, by increasing circulating steroids (Keller et al., 1983; Irwin et al., 1989; 
Weiss et al., 1989). The finding by Sundar et al. (1989) suggested that neural pathways, possibly autonomic innervation, contributed to brain IL-1-induced immunosuppression. This was confirmed by the results of Experiment 2 of the present paper. In this study, blockade of the sympathetic nervous system by chlorisondamine diminished the suppression of cellular immune responses that normally occurs to intraventricular IL-1. However, in that ganglionic blockade reduced immunosuppression following IL-1 infusion only partially, the present findings also confirm that other factors (i.e., elevation of plasma steroids) do contribute to brain IL-1-induced immunosuppression. Regarding the role of CRF, activity of this peptide in the brain is known to stimulate the sympathetic nervous system (Brown et al., 1982); therefore, it is consistent with known actions of this peptide in the brain that it would activate both the pituitary-adrenal axis and the sympathetic nervous system. As found in Experiment 1, complete blockade of CRF (as evidenced by blockade of IL1 -induced steroid elevation) totally blocked the effect of intraventricular IL-1 on cellular immune responses. Consequently, the evidence indicates that IL-1 in the brain produces suppression of cellular immune responses by activating CRF release in the brain, which in turn mediates immunosuppression by stimulating both the pituitary-adrenal axis and autonomic nervous pathways.

Of considerable interest is the question of where the infused IL-1 acts to initiate the responses leading to immunosuppression. One possibility that needed to be addressed was that IL-1 did not act on cells of the CNS, but, rather, affected infiltrating leukocytes at the site of the indwelling cannula in the lateral ventricle. According to this hypothesis, a consequence of cannula implantation 4-5 d prior to infusion is that various cells normally present in peripheral circulation (i.e., monocytes, lymphocytes) gain access to the ventricular system as a result of the surgery and accumulate at the site where the indwelling cannula penetrates into the ventricle. When IL- 1 is then infused, it acts upon these cells to cause them to release either CRF or soluble factors that stimulate CRF, and immunosuppression then results. To test whether this might be correct, we injected IL-1 into the lateral ventricle without using an indwelling cannula. For this procedure, a guide cannula that terminated $3.0 \mathrm{~mm}$ above the lateral ventricle was implanted $4-5 \mathrm{~d}$ prior to infusion; at the time of infusion, a needle was inserted through the guide, which penetrated into the ventricle, and IL-1 was then introduced immediately. The results of this study are shown in Figure 6. When IL-1 was infused into the ventricle in this manner, which precluded accumulation of peripheral cells around an indwelling cannula, IL-1 rapidly suppressed NK cell activity and also elevated plasma corticosteroid concentration just as had occurred when IL-1 was introduced through an indwelling cannula. Thus, we found no indication that peripheral cells accumulating in the ventricular system play a role in immunosuppression produced by IL- 1 in the brain.

Turning to the issue of where in the CNS the IL-1 acts to produce immunosuppression, the ability of antibody to CRF injected in the ventricle to block effects of IL-1 may provide some clues. If the antibody molecule could not readily diffuse out of the ventricular system to permeate the brain, the fact that CRF antibody introduced into the ventricular system was sufficient to block the immunosuppressive effects of intraventricular IL- 1 indicates that the pathway utilized by intraventricular IL- 1 depends either on CRF close to the ventricular system or on CRF released into the ventricular system. As discussed else-

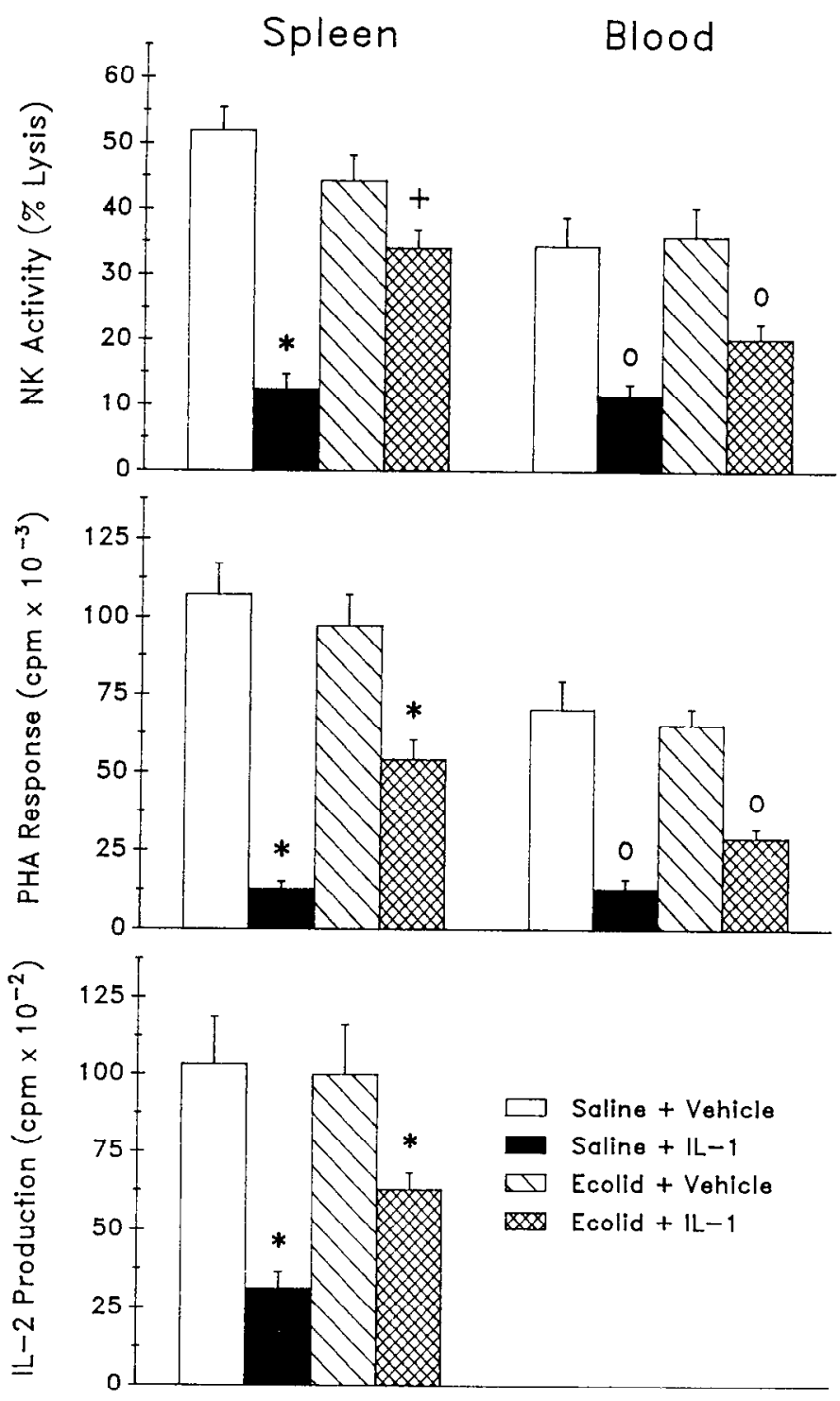

Figure 5. Various cellular immune responses in animals infused with IL-1 or vehicle following injection of chlorisondamine $(3.0 \mathrm{mg} / \mathrm{kg})$ or physiological saline vehicle. Effects in splenic and blood lymphocytes are shown for NK cell activity (50:1 effector : target cell ratio), PHA response, and IL-2 production. Mean and SE for cach group are shown. Asterisk, differs significantly (at least $p<0.05$ ) from each of the other 3 groups; open circle, differs significantly from each vehicle-infused group; plus, differs significantly from each group infused with saline.

where (Sundar et al., 1989), it has been suggested by several authors (Blatteis et al., 1983; Coceani et al., 1988; Katsuura et al., 1988b) that the action of IL-1 in the brain may occur by IL-1 acting at the circumventricular organs, particularly to organum vasculosum lateral terminalis (OVLT). That antibody to CRF introduced into the lateral ventricle completely blocked the immunosuppressive effects of IL-1 is consistent with the possibility that IL-1 acted in the vicinity of the OVLT. On the other hand, it should be noted that it was necessary to infuse enough antibody (i.e., $2.25 \mu \mathrm{g}$ ) to neutralize $5.2 \mathrm{ng}$ CRF in order to block brain IL-1-induced immunosuppression, which may mean that the infused antibody had to reach some site distal to the ventricular system in order to be effective. 


\section{NK ACTIVITY STEROID RESPONSE}

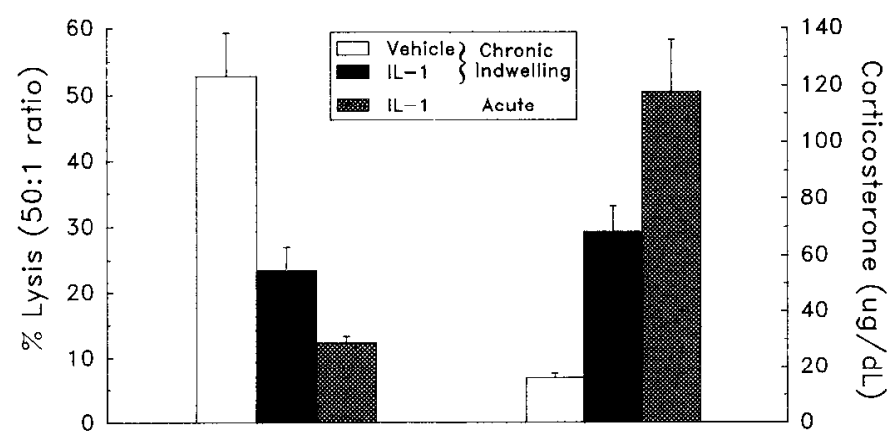

Figure 6. Results showing that suppression of cellular immune responses and stimulation of pituitary-adrenal axis does not depend on presence of cannula implanted in ventricle prior to infusion. Shown above are NK cell activity of splenic lymphocytes and plasma corticosterone concentration of animals that were infused with vehicle $(N=$ 4) or IL-1 $(N=3)$ through an indwelling ventricular cannula or IL-1 by acute penetration of the lateral ventricle just prior to infusion $(N=$ 3). Mean and SE for each group are shown. Vehicle and IL-1 via indwelling cannula were infused as described for other experiments in this paper, though a higher dose of IL-1 $(0.5 \mathrm{ng})$ was given in this study when increased concentration of the IL-1 was supplied by the vendor (Genzyme). For acute penetration of the lateral ventricle (LV), a guide cannula terminating approximately $3.0 \mathrm{~mm}$ above the $\mathrm{LV}$ was implanted earlier; for infusion, a needle protruding $3.5 \mathrm{~mm}$ below the guide cannula was inserted, and the IL-1 was immediately infused (solution introduced over same time period as through indwelling cannula). Because it could not be determined that the needle had entered the LV at the time of infusion and so the possibility of missing the LV was greater than for implanted cannulae, acutely injected animals were infused bilaterally. All animals were killed by decapitation $30 \mathrm{~min}$ after infusion. Relative to the effects produced by infusion of IL-1 through an indwelling cannula, IL-1-induced suppression of NK cell activity and elevation of plasma corticosterone seen after acute penetration of the ventricle was at least as large.

\section{References}

Bartolome J, Mills E, Lau C, Slotkin TA (1980) Maturation of sympathetic neurotransmission in the rat heart $\mathrm{V}$. Development of baroreceptor control of sympathetic tone. J Pharmacol Exp Ther 21 5:596600 .

Berkenbosch F, Oers JV, Rey AD, Tilders F, Besedovsky H (1987) Corticotrophin-releasing factor-producing neurons in the rat activated by IL-1. Science 238:524-526.

Bernton EW, Beach JE, Holaday JW, Smallridge RC, Fein HG (1987) Release of multiple hormones by a direct action of IL-1 on pituitary cells. Science 238:519-521.

Besedovsky H, Rey AD, Sorkin E, Dinarello CA (1986) Immunological feedback between IL-1 and glucocorticoid hormones. Science 233: $652-654$.

Blatteis CM, Bealer SL, Hunter WS, Llanos-Q J, Ahokas RA, Mashburn TA (1983) Suppression of fever after lesions of the anteroventral third ventricle in guinea pigs. Brain Res Bull 11:519-526.

Breder CD, Dinarello CA, Saper CB (1988) IL-1 immunoreactive innervation of the human hypothalmus. Science 240:321-324.

Brown MR, Fisher LA (1985) Corticotrophin releasing factor: effects on the autonomic nervous system and visceral systems. Fed Proc 44: 243-248.

Brown MR, Fisher LA, Spiess J, Rivier C, Rivier J, Vale W (1982) Corticotrophin releasing factor: actions in the sympathetic nervous system and metabolism. Endocrinology 111:928-931.

Coceani F, Lees J, Dinarello CA (1988) Occurrence of IL-1 in cerebrospinal fluid of the conscious cat. Brain Res 446:245-250.

Cohen JJ, Crnic LS (1982) Glucocorticoids, stress, and the immune response. In: Immunopharmacology and the regulation of leukocyte function (Webb D, ed), pp 61-91. New York: Marcel Dekker.
Dinarello CA (1984) Interleukin-1. Rev Infect Dis 6:51-95.

Felten DL, Felten SY, Bellinger DL, Carlson SL, Ackerman KD, Mad den KS, Olschowski JA, Livnat S (1987) Noradrenergic sympathetic neural interactions with the immune system: structure and function. Immunol Rev 100:225-260.

Gillis S, Crabtree GR, Smith KA (1979) Glucocorticoid-induced inhibition of T-cell growth factor production: I. The effect on mitogeninduced lymphocyte proliferation. J Immunol 123:1624-1638.

Gillis S, Ferm MM, Ou W, Smith KA (1978) T-cell growth factor: parameters of production and a quantitative microassay for activity. J Immunol 120:2027-2031.

Irwin M, Jones L, Britton K, Hauger RL (1989) Central corticotrophin releasing factor reduces natural cytotoxicity: time course of action. Neuropsychopharmacology 2:281-284.

Katsuura G, Gottschal PE, Dahl RR, Arimura A (1988a) Adrenocorticotropin release induced by intracerebroventricular infusion of recombinant human interleukin-1 in rats: possible involvement of prostaglandin. Endocrinology 122:1773-1779.

Katsuura G, Koves K, Gottschall PE, Arimura A (1988b) The organum vasculosum lamina terminalis (OVLT) and the preoptic anterior hypothalamus area (POA) are primary sites for IL-1-induced ACTH release. Soc Neurosci Abstr 14:756.

Keller SE, Weiss JM, Schleiffer SJ, Miller NE, Stein M (1983) Stressinduced suppression of immunity in adrenalectomized rats. Science 221:1301-1304.

Kirk R (1969) Experimental design: procedures for the behavioral sciences. Belmont, CA: Brooks/Cole.

Krueger JM, Walter J, Dinarello CA, Wolff SM, Chedid L (1984) Sleep promoting effects of endogenous pyrogen (IL-1). Am J Physiol 246: R994-999.

Mills E, Smith PG (1986) Mechanisms of adrenergic control of blood pressure in developing rats. Am J Physiol 250:R 188-192.

Murphy BEP (1967) Some studies of the protein-binding of steroids and their application to the routine micro and ultra-micro measurement of various steroids in body fluids by competitive protein-binding radioassay. J Clin Endocrinol Metab 27:973-990.

Naylor MR, Krishnan KRR, Manepalli AN, Ritchie JC, Wilson WH, Carroll BJ (1988) Circadian rhythm of adrenergic regulation of adrenocorticotropin and cortisol secretion in man. $\mathbf{J}$ Clin Endocrinol Metab 67:404-409.

Reynolds WC, Timonen T, Herberman RB (1981) Natural killer (NK) cell activity in the rat. I. Isolation and characterization of the effector cells. J Immunol 127:282-287.

Riley V, Fitzmaurice MA, Spackman DH (1981) Psychoneuroimmunologic factors in neoplasia: studies in animals. In Psychoneuroimmunology (Ader R, ed), pp 31-47. New York: Academic.

Sapolsky R, Rivier C, Yamamoto G, Plotsky P, Vale W (1987) Interleukin-1 stimulates the secretion of hypothalamic corticotropinreleasing factor. Science 238:522-524.

Seidler FJ, Slotkin TA (1979) Presynaptic and postsynaptic contributions to ontogeny of sympathetic control of heart rate in the preweanling rat. J Pharmacol 65:431-434.

Smith PG, Poston CW, Mills E (1984) Ontogeny of neural and nonneural contributions to arterial blood pressure in spontaneously hypertensive rats. Hypertension 6:54-60.

Sundar KS, Becker KJ, Cierpial MA, Carpenter MD, Rankin LA, Fleener SL, Ritchie JC, Simson PE, Weiss JM (1989) Intraventricular infusion of intcrlcukin-1 rapidly decreases peripheral cellular immune responses. Proc Natl Acad Sci USA 86:6398-6402.

Tobler I, Borbely AA, Schwyzer M, Fontana A (1984) IL-1 derived from astrocytes enhances slow wave activity in sleep EEG of the rat. Eur J Pharmacol 104:191-192.

Weiss JM, Simson PG, Hoffman LJ, Ambrose MJ, Cooper S, Webster A (1986) Infusion of adrenergic receptor agonists and antagonists into the locus coeruleus and ventricular system of the brain. Effects on swim-motivated and spontaneous motor activity. Neuropharmacology 25:367-384.

Weiss JM, Sundar SK, Becker KJ (1989) Stress-induced immunosuppression and immunoenhancement: cellular immune changes and mechanisms. In: Neuroimmune networks: physiology and disease (Goetzl EJ, Spector NH, eds), pp 193-206. New York: Liss. 